\title{
Eurhythmy and life stories as a prevention against Alzheimer
}

\begin{abstract}
In this study, an intervention programme in order to prevent against Alzheimer has been applied to elderly persons, starting from Eurhythmy and by means of the use of 'Life Stories'. Effects of the intervention on cognitive abilities and quality of life of elderly persons have been analyzed. Participants in the study were 11 individuals aged 63 to 92 . The intervention program was carried out in 14 sessions, and the cognitive abilities and the quality of life evaluated before starting the intervention and after finishing it. Results in general indicate that cognitive abilities in adults are preserved when applying said Alzheimer prevention program.
\end{abstract}

Volume 3 Issue 6 - 2018
Ana-Mercedes Vernia-Carrasco

Correspondence: Ana-Mercedes Vernia-Carrasco, Education deparment, Area of Didactics of Musical Expression, Jaume University, Spain,Tel 61620068I, Email vernea@edu.uji.es

Received: July 17, 2018 | Published: November 26, 2018

Keywords: eurhythmy, life stories, alzheimer, cognitive abilities, quality of life

\section{Introduction}

Alzheimer's disease (AD) is a neurodegenerative disease which interferes in the ability to carry out daily life activities due to gradual deterioration of memory, language, temporo-spatial orientation and visual spatial functions. ${ }^{1}$ Such disease affects approximately $18.7 \%$ of people between 75 and 84 and, $47.2 \%$ in over 85 year old populations ${ }^{2}$ Due to the fact that the world's population life expectancy is increasing, above all in the western world, ${ }^{3}$ it is expected that in the future the risk of showing $\mathrm{AD}$ or diseases related to dementia will increase.

Currently, however, life expectancy raise and the improvement of social conditions which society, above all in the occidental world, has experienced have made possible the constant increase in the number of elderly people. With the intention to improve this group's quality of life (QOL), we have taken action aiming at meeting the new challenges. The fact that a high percentage of the Spanish population is old, provides a new situation in which resources are redistributed to develop a wide range of initiatives channeled into making present and future elderly people's life better. ${ }^{4,5}$

In the context of social services, sanitation and education, the concept of QOL has been acquiring great importance as an investigation target. Action taken in the last decades has allowed the evolution of the QOL concept and its action field. Currently, the QOL is a common target for service users, professionals, organizations or politicians. ${ }^{6}$ Hence, the concern for QOL leads the World Health Organization (WHO) (1992) to define the QOL as: "individuals' perception of their position in life in the context of the culture and value system in which they live and in relation to their goals, expectations and standards and concerns." (WHOQOL) It must be taken into account that QOL thrives when the subject has all their needs covered and that the QOL for elderly persons involves society in general and families' collaboration.

In the study conducted by Ramos-Esquivel ${ }^{7}$ they reached the conclusion that QOL can interact with the old age by sharing concepts and meanings. There are connections between the amount of years people live and the elements socially shared, such as the lack of work or physical autonomy, which cause negative feelings towards this absence. These authors, although they admit the limitations of their study type, highlight the existent concern for the investigation into how the old age is experienced in the current social conditions.

It must be taken into account that, although "old age" and "aging" are phrases from the same family, they have different implications. The "old age" is a stage in life, the same as the childhood, adolescence or adulthood, so it is about a state that has been lived at a temporary moment in which a series of changes, common of this period, take place. The term "aging" is not a state, as Agulló says, ${ }^{8}$ it is a process that is brought to fruition along life and implies the idea of continuity and the action of getting older. Despite there are losses in many vital functions, others stay the same or even rise.

According to Fernández-Ballesteros, ${ }^{9}$ and Pérez,${ }^{10}$ there are three types of "aging", firstly, "normal aging" which would cover gradual biological, psychological and social changes common for the age. These changes are unavoidable and intrinsic. Secondly, there is the "pathological aging" which would cover the changes that do not belong to "normal aging" and are produced by illnesses, bad habits or dementia. In some cases these changes can be prevented or are reversible. Finally, it is the "optimum aging" which is the process that takes place in normal conditions. This last aging type is present in those persons who care for and make possible the proper development of their physical and psychological health by doing physical exercise or taking part in programs like the one here presented, in which they work their cognitive skills, improve their self-esteem, and keep healthy habits avoiding dependence and isolation.

In our opinion, a connection with dementia could be established as Prieto et al. ${ }^{11}$ point out, stating that dementia grows exponentially with age; so in a few years this disease, which according to statistics is the main reason for elderly adults' disability, may become a worldwide epidemic. In general terms, the prevalence of dementia is under the $2 \%$ in people between 65 and 69 years old; this value doubles every 5 years standing between $10-17 \%$ in persons between 80 and 84 years old, and reaching a $30 \%$ in persons over 90 years old.

One of the most common dementias, which means a dwindling cognitive function of a person or in their mental capacity to think, 
reason, remember and independently carry out daily tasks that they used to do, is Alzheimer's disease (AD). This disease, according to the WHO "with its devastating impact on people with dementia, their families, their communities and national health system, it represents a public health crisis"12 The study conducted by Lobo ${ }^{13}$ in Spain, in which they monitored a 4057 subject cohort who were over 55 years old, lived in Zaragoza and were cognitively intact, shows that the rate of effect of dementia was of 8.6 per 1000, being AD's rate of 5.4 per 1000. This rate is lower than the one emphasized in former studies on northeastern Europe13. De Pedro-Cuesta et al. ${ }^{14}$ also carried out a study aiming at the center and northeast of Spain, where they tried to reveal in which degree populations in Spain are affected by the most common dementias. They concluded that the prevalence of dementia and $\mathrm{AD}$ in the above mentioned areas, grow with age and it is higher in women, being dementia more frequent than Alzheimer. These authors stress the impact in Spain, there being 600.000 people who suffer from dementia and around 400.000 who suffer from Alzheimer.

\section{Dementia and alzheimer's disease (AD)}

As age evolves it generates the loss of capabilities, and in some cases dementias. López-Pousa ${ }^{15}$ defines dementia as "an acquired syndrome produced by an organic cause able to provoke a persistent deterioration of the superior mental functions which leads to a functional incapability in both the social and labor field, in people who do not suffer from any alteration at consciousness levels". Generally speaking, society is becoming more aware of the situation helped by the scientific community which is becoming more and more sensitive to this problem.

In the European Parliament Resolution ${ }^{16}$ for a European initiative about AD and other dementias (2010/2084 (INI)), it is considered that in 2030 they will reach 65.7 million people affected by AD. They provide for difficulties for early detections; the number of people who suffer from Alzheimer has been underestimated. This kind of disease is one of the main causes of disability and dependence in elderly people, together with the absence of social life and the rise of life expectancy, the number of affected is multiplying. Dementia is expected to become one of the main challenges for the national social and health systems' sustainability in the next decades, including long-term assistance and non-professional care. Early detection could help to control the public health expenses in all Europe. Moreover, prevention of dementia through modifiable interventions should be a priority and special attention to preventive factors must be paid, such as a healthy diet and, encouragement of physical and cognitive activity among others. On the other hand, patients' QOL improvement is usually related to the emotional state of their relatives.

The revision of the DSM-IV-R (American Psychiatric Association, 2000) classifies dementias in six groups: Alzheimer, vascular, caused by general medical conditions, substance induced, multiple etiologies and non-specified dementia. ${ }^{17}$

\section{Life stories}

Apart from the effectiveness of pharmacological treatments, we appreciate that more non-pharmacological treatments are applied every day. This is due to the fact that active methodologies that strengthen culture and intelligence exercise, have a direct impact on the effect of AD helping the patients to lead a better and more human life. ${ }^{18}$ The article here presented shows the effects of the applied program, in which Life Stories and Eurythmy have been the pillars on which our investigation is settled.

Life Stories can be understood as an instrument inside the therapies of reminiscence, being the latest understood as the adaptative response characterized by having to think and tell one's own experiences bringing past memories to the present. The goal is to remember, regardless of its perfection or the spatial-temporal location. It is intended to obtain some improvement of the capability to remember by letting the patients be creative, potentiating interaction, dialogue, self-esteem and wellbeing.

Although at the beginning reminiscence therapies were carried out with elderly people without any outstanding problem in their aging in order to make them work their memory, ${ }^{19}$ time after that Kiernat ${ }^{20}$ developed them with people with dementia. Studies conducted by Baines and cols. ${ }^{21}$ show modest results in which a slight improvement at behavioral levels is appreciated.

The existent techniques to recover memory in patients with $\mathrm{AD}$ are based on the fact that memory loss is gradually produced and its intensity is variable at early stages of the disease. In general, it affects two types of memory that are classified inside the explicit memory: episodic memory and semantic memory. ${ }^{22}$ There are studies ${ }^{23}$ which have proved that $\mathrm{AD}$ patients can improve their memory by means of cognitive support along their learning and the recovery of the information at early stages of the disease.

Persons are a complex reality constituted by a history that is the result of the experienced built up in the course of time based on the dialog with others. Emotional, social and moral aspects along with cognitive aspects are also present. Life Stories are based on the dialog among people recreating lived experience. Each Life Story is the interpretation that each person does at a moment in time by reconstructing their own story. The subject is placed in the center of the process being the source of knowledge, and they do it in a social, political, temporal and cultural specific context.

Life Stories and the biographical and narrative investigation give value to people's voices. They are provided with an outstanding prominence in the investigation by setting the construction of the experience from their own knowledge. Hence, the subject is presented as a socio-historical construction, meanwhile the dialog becomes a condition to achieve the social construction and the experience is the expression of our present given the construction of our own past. ${ }^{24}$

In order to understand the subject, we must take into account that we cannot do it in an individual way, but in a collective way and from the dialog. Thus, in order to construct the individual subject we must do it, as Shopenhauer, ${ }^{25}$ in a collective and global manner. Life Stories make it possible to understand the political, cultural and social contexts in which they were created. The relationships we establish with other people help us to convey meaning to our own experiences. Telling the events we have lived, experienced, or been through, is the means people have to reaffirm what we are at the present moment.

When a person is telling their Life Story, it must be taken into account that they are doing it from their own point of view. They will tell what they think is more appropriate, outstanding or what they remember at that moment. A relationship between both actors is established; the investigator and the investigated. In our case, a third element must be added, the group mates. The passing of time makes it 
possible to discover, dialog and establish a relationship of trust where sharing life experiences creates in each participant a positive feeling through which the individual becomes collective.

Active listening, dialog and written expression of their life experiences make it possible for them to nourish from individual lives. In this process, we must understand, dialog and form a union with the investigated. ${ }^{26}$ In order to be successful, trust between the subjects themselves and each member of the group must be enabled.

As they share their experience they discover themselves, know themselves better and dialog flows. The willingness to share their experiences shows. Each member starts creating their own story helped by the other's stories, making experiences that had been forgotten flow when they hear their partners'. Reminiscence comes true. Life Stories make it possible for what has been told to show lived experiences.

Credibility in the process must be based on transparency, showing how it has been developed, how "life stories have come to life". ${ }^{27}$ In our case, each participant recalls experiences and events from their life, writes them down helped by the interview outline that has been followed. It is when they share it with their own partners; when what they have done becomes meaningful; when they recognize as theirs everything they have recounted. This process has been developed as described and also initiating the dialog about different moments in their lives, which helps them recall their experiences when hearing what their partners tell.

Life Stories make it possible to exercise memory, recall, recover information, value it and become aware of what patients are living with the people they currently are, their personality, attitudes towards life and, relationships with others.

The carrying out of a life story implies a process of reflection, which leads to discovering the meaning of the lived events. It is in this process where events are reinterpreted; it is in this catharsis when the self personal identity is built. As Vázquez says. ${ }^{28}$ "when a person recalls something, they hold, reproduce, extend, father, alter and transform their relationships through their discourse".

Regardless of their moment in life, we intend our participants to be protagonists of their own lives, which implies a pro-active attitude leaving aside the "laisse faire". We try them to stop waiting for others to do something and to be themselves the ones who decide to write their own life story. Life stories are a "process of restitution" which gives the person their experience back. Telling in first person their life story is a brain activation mutual restitution process that is useful for both; the one who tells it and the one who listens to it. Both can keep what has been told about the others' historical and social moments, when the events told took place and, tell them and live them in the present as if they were their own memories. ${ }^{29}$

It is of fundamental importance to supply with the needed means in order to notice the first signs of the disease, to look into an early diagnose and access programs and interventions. Paying more attention to $\mathrm{AD}$ prevention and, contributing to the development of interventions through life stories and eurhythmy, as we are trying to show on this project, can slow down the progress of the disease and delay the severe stage as a last resort.

\section{Eurhythmy, rhythmic and body expression through music}

As explained by De la Rubia et al., ${ }^{30}$ Alzheimer is one of the diseases that most worries our society. Treatments help, but other therapies to improve the symptoms of this disease, such as music among them, are searched. These authors carried out a study about the benefits of music by means of a questionnaire that measured depression and anxiety related to stress and, happiness related to wellbeing before and after some music therapy sessions. Significant improvement in patients was achieved.

There are studies that show the benefits of music, for instance, Hars et al. ${ }^{31}$ who, in order to lead their investigation, start from the premise that music is beneficial to the multitasking training, having a bearing not only on the cognitive functioning but also on the state of mind. In their investigation, they count on adults from 65 years old on. The conclusion they reached after 6 months of intervention, one hour per week, was that the use of music from Dalcroze's methodology improved the cognitive function and the waning of anxiety compared to other control groups.

According to Vernia et al. ${ }^{32}$ elder adults tend to passivity, loneliness and isolation, being also prone to degenerative diseases. For this reason she suggests a series of activities through Eurhythmy (body expression by means of Musical Education) which allow mind and body in elderly people to activate. Vernia recommends this work to be accompanied on the one hand by specialized professionals in the pedagogue Dalcroze's (Eurhythmy) methodology and, on the other hand by a medical team who can assess the process and results of participants.

In the study by Trombetti et al..$^{33}$ it could be observed how the times elderly people fell down could be reduced through music, specifically by using Dalcroze's methodology, whose foundation is body movement as musical expression. This study was carried out for 12 months with 134 participants chosen randomly and older than 65 at risk of falls. Some were assigned the control group and others the intervention group. Six months later a waning in the falls could be observed in the intervention group. Another study that emphasizes music and its connection with elderly people's falls, was conducted by Beauchet et al. ${ }^{34}$ In this study it was stressed that many participants diminished their ability to count when doing a double task (walking and counting backwards) whereas a lower percentage increased this ability. However, the really significant discovery was a better performance in their talking while they were walking compared to their talking when they were still. Although more investigation needs to be done in this field, these authors bear in mind Dalcroze's methodology, whose foundations involve multitasking exercises from music, that is to say, the practice of rhythmics through music.

Music may have a therapeutic value in patients with $\mathrm{AD}$ according to Lord and Garner, ${ }^{35}$ who worked with three groups of people affected by this disease. Subjects who participated in a Big band, performing music from the $20 \mathrm{~s}$ and $30 \mathrm{~s}$, showed a better ability to remember events from their personal past compared to the other two groups (one of them drew and painted and the other did puzzles). Moreover, the first group looked happier. As Jacobsen et al. ${ }^{36}$ the mechanisms and neural substrates of musical memory are still little-known. These authors conducted an investigation with 32 participants, showing among their conclusions, that the regions identified to codify musical memory belonged to the areas that showed substantially minimal cortical atrophy compared to the rest of the brain. In addition, given the superimposition observed in the musical memory regions compared to the areas which are relatively safe from $\mathrm{AD}$, the current 
finds can explain the surprising preservation of musical memory in this neurodegenerative disease.

By means of a piano and using it with people from 60 to 85 years old, Burgos et al. ${ }^{37}$ showed that this musical instrument could be useful for an effective cognitive intervention related to age and cognitive deterioration. These authors also associate aerobic exercise with a slower cognitive deterioration, although the aim of their investigation was to preserve or keep cognitive skills by using music, and prevent memory loss through the piano learning process. The work led by Kydd et al. ${ }^{38}$ was also aimed at people who suffered from $\mathrm{AD}$ or any disease related to this dementia which involves behavior such as depression, isolation, anxiety, emotional lability, confusion and memory difficulties. By means of music therapy participants were helped to improve their QOL and their relationships with the people around them, concluding that music therapy can facilitate a better adaptation of life to a specific context.

In our opinion, patients with $\mathrm{AD}$ can stimulate themselves by means of songs that are familiar to them and, with constant practice they can even learn new songs despite not being able to remember recent conversations. In Prickett and Moore's study ${ }^{39}$, they dealt with different aspects of verbal memory with and without music; with verbal material from their childhood associated to music, that is to say, words which had always been associated to a melody or chant. In general, patients remembered the words from the songs outstandingly better than they remembered spoken words, including rhymed language ${ }^{39}$ Following this line, the investigation carried out by York ${ }^{40}$ was aimed at assessing patients with Alzheimer by using music and achieving a reduction of anxiety, memory functions preservation, positive affection raise and creative self-expression, which have been all mentioned as possible benefits of music therapy interventions.

\section{Program description (daily practice)}

The program has been developed throughout 28 weeks, in sessions of one hour a week, in which eurhythmy has been randomly worked in 14 of them and, life stories in the rest. We will show as an example the activities done in one of the sessions of each part, since, although they have been developed in a coordinated way, their practical application differs in content.

Eurhythmy: the session starts with some relaxation minutes listening to music which has the following features; slow tempo and moderate intensity. The next 15 minutes are used to warm up their voice by means of vocalization exercises and others such as singing the "C major" diatonic scale. They go on to the body warm-up by following the rhythm of the music that is being listened to. With this rhythm we work coordination of hands and feet. It is important to point out that, the people who took part in the project had limited mobility or were even in a wheelchair. In this case, mobility in lower extremities was limited to feet and heel movement. The session ends with the interpretation of songs proposed in the previous session by the participants themselves. The importance of these activities lies in the work on laterality, in doing different activities simultaneously having a bearing on both cerebral hemispheres. While we are singing, we accompany ourselves with a rhythm (body percussion) apart from paying attention to the group, which requires coordination and concentration. Participants get so involved that they help each other, not only in the rhythmic coordination but also in the recovery of songs' lyrics.

Life stories: we start the activity with the recall of their lives in a guided way, that is, in each session the most outstanding vital moments are worked, such as childhood, adolescence, adulthood, work, etc. In order to execute it, we used Martí and Nebot's manual..$^{41}$ The fact of sharing out loud each of the participants' life experiences increases the active listening skills, stimulates respect and pro-social skills. This process is basic for the next stage, the writing. The development of hand-eye coordination and reading and writing is conducted by telling their own life experiences. Bearing in mind the limited mobility some of the participants have and the hearing difficulties, the help from the Primary Teacher's degree volunteer students at Jaume I University has been essential. The exchange of intergenerational experiences allows the acquisition of knowledge, emotions and new feelings. The sessions conclude with an exchange of opinions assessing the task developed in the group.

\section{Methodology}

\section{Participants}

Inclusion criteria for the prevention program participants were as follows:

1. Belong to the residential home.

2. Aged from 63 on.

3. Showing a normal cognitive state, mild or moderate deterioration.

Initially the sample was of $\mathrm{N}=30$, once the authorization from relatives and persons was obtained, five of these participants did not meet some of the inclusion criteria and, two of the participants deceased during the intervention period. So the final sample was composed of 23 elderly people.

Both participants and relatives provided us with a written authorization for the participation in the program. The assessment sessions took 20-30 minutes. In these sessions, cognitive functions and participants' QOL were assessed.

The sample was composed of 23 elderly people, aged from 63 to 98, who resided in Azahar del Mediterraneo Residential Home in Castellon province. Participants were $8.7 \%$ men and $91.3 \%$ women. Mean age of participants was $\mathrm{M}=83.70$ years $(\mathrm{SD}=8.01)$. Moreover there were no significant differences in age $(t(23) 1,080, p=.292)$, gender $\left(\chi^{2}(1, \mathrm{~N}=23)=.122\right)$ or cognitive deterioration $(\chi 2(1, \mathrm{~N}$ $=23)=.065$ ) (Figure 1) (Figure 2).

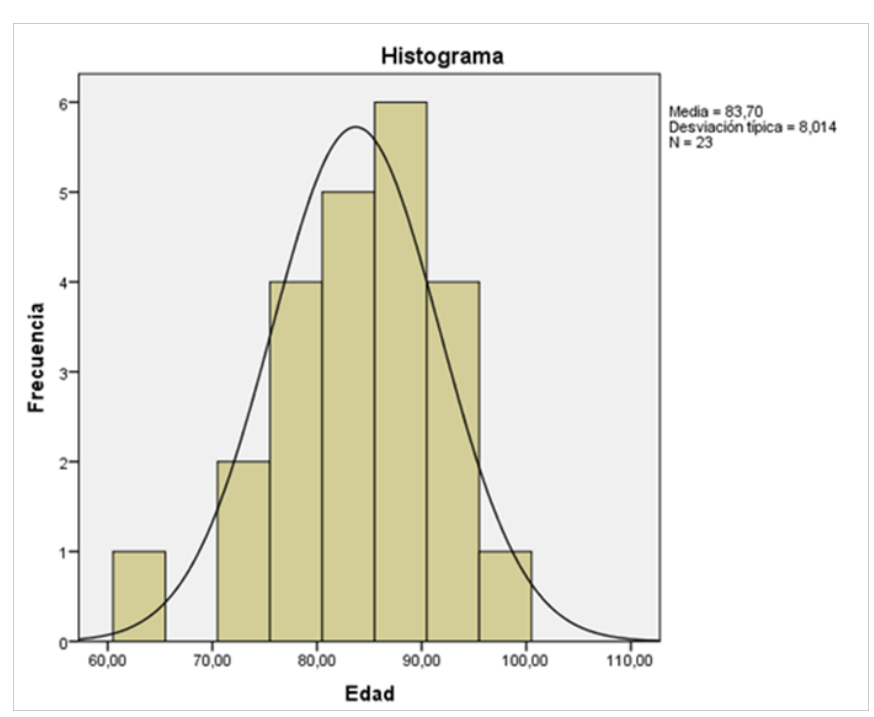

Figure I Age of full sample with/without intervention. 


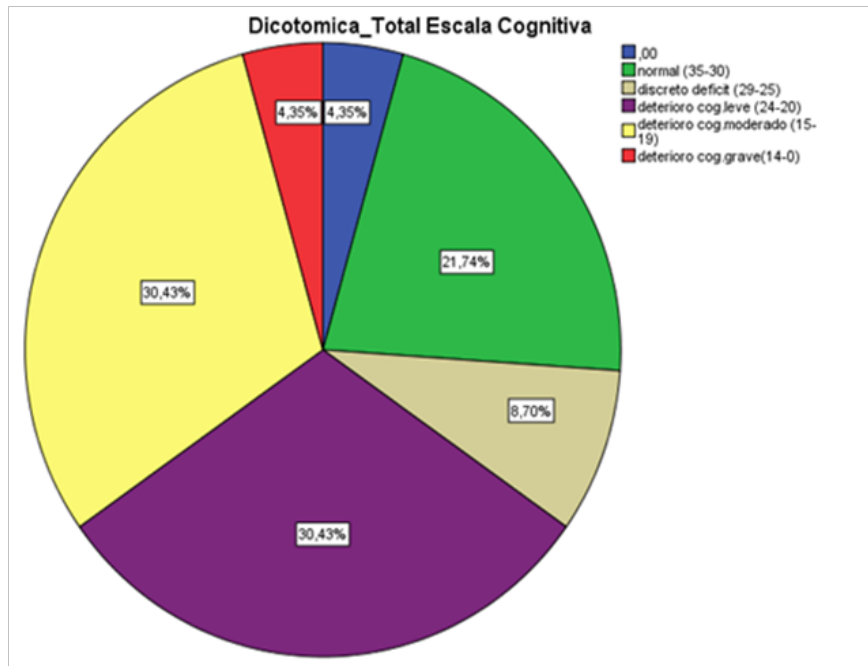

Figure 2 Full sample Cognitive Scale with/without intervention.

\section{Procedure}

\section{Assessment tools}

\section{Mini mental state examination}

The Spanish version of the Mini Mental State Examination used ${ }^{42}$; adapted for Spain by Lobo et al., ${ }^{43}$ is composed of 30 items, which assess six cognitive skills (time orientation, spatial orientation, binding, concentration and calculation, memory and language and, construction). Each correct answer is given one point, the maximum punctuation that can be obtained is 30 points. Application time is 5-10 $\min$.

Cubrecavi questionnaire ${ }^{44}$ assesses in a short time, different elements of QOL in elderly people. This questionnaire is based on the multidimensional concept of quality of life and health proposed by WHO. It is composed of 21 subscales, divided into the following nine dimensions: 1) Health (subjective, objective and psychic), 2) Social integration, 3) Functional skills, 4) Leisure activities, 5) Environmental quality, 6) Life satisfaction, 7) Education, 8) Income and 9) Social and health services. Criteria were established from a sample of 1000 people elder than 65 who allowed a comparison with a normative group about the quality of life of the subject. This questionnaire was applied individually starting from an interview with a professional. Application time is $20 \mathrm{~min}$. approximately.

\section{Results}

Computer application SPSS 21.0. has been used in order to carry out the statistical analysis. The test Kolmogorov-Smirnov was used in all variables to check that the data fulfilled all the statistical normality criteria.

Results obtained from this test show that Cubrecavi questionnaire's variables Cohabitation Satisfaction (K_S $(23)=1.477 ; p=.025)$, Social Relationships Satisfaction $(\mathrm{K}-\mathrm{S}(23)=2,014 p=.001)$, Activity Level (K_S(23)= 2,225;p=.000), Activity Satisfaction (K_S $(23)=1,948 ; p=.00$ ), Post Environment Quality (K_S(23)=1,769; $p=.004)$, Post Environmental Elements Satisfaction (K S $(23)=$ $2,219 ; p=.000)$, Post Housing General Satisfaction (K_S(23)= 2,007; $p=.001$ ), Post Life Satisfaction (K_S $(23)=1,405 ; p=.038)$, Education $\left(\mathrm{K} \_\mathrm{S}(23)=1,795 ; p=.003\right), \quad$ Post Education $\left(\mathrm{K} \_\mathrm{S}(23)=1,670\right.$; $p=.008$ ), Income (K_S(23) $=2,486 ; p=.000)$; and Mini Mental State Examination questionnaire's variables, Binding (K_S $(23)=2,585$; $p=.000)$, Post Binding $\left(\mathrm{K} \_\mathrm{S}(23)=1,941 ; p=.001\right)$, Memory $\left(\mathrm{K} \_\mathrm{S}(23)=1,532 ; p=.018\right)$, Post Memory $\left(\mathrm{K} \_\mathrm{S}(23)=1,838 ; p=.002\right)$, don't show statistical normalcy.

That is the reason why, in Table 1 below, we show the tendency of all the variables' means used in the current study and any significant difference there can be (Table 1).

Results show that participants improve their social relationships satisfaction, life satisfaction, leisure activities and level of activity (Table 2).

Table I Pre and Post Quality of Life variables of participants who collaborated in the study

\begin{tabular}{|c|c|c|c|c|c|}
\hline Variables & Intervenidos(N=I I) M(SD) & Mdn (IQR) & Comparación (N= I 2) M(SD) & Mdn(IQR) & $\mathbf{t} / \mathbf{U}$ \\
\hline Health & $2,98(0,30)$ & - & $2,77(0,46)$ & - & $t(I, 22)=-1,250 \mathrm{~ns}$ \\
\hline Post_Health & $2,65(0,36)$ & - & $2,39(0,60)$ & - & $t(1,22)=-1,179 n s$ \\
\hline Subjective_Health & $2(1,49)$ & - & $2,08(0,99)$ & - & $t(1,22)=0,157 \mathrm{~ns}$ \\
\hline Post_Subjective Health & $2,88(0,60)$ & - & $\mathrm{I}, 83(0,83)$ & - & $t(I, 22)=-3,212 * *$ \\
\hline Objective Health & $3,2 I(0,38)$ & - & $3,06(0,47)$ & - & $t(I, 22)=-0,779 \mathrm{~ns}$ \\
\hline Pos_Obj_Hea & $2,93(0,30)$ & - & $2,66(0,79)$ & - & $t(I, 22)=-I, 158 \mathrm{~ns}$ \\
\hline Psychic Health & $2,87(0,52)$ & - & $2,97(0,83)$ & - & $t(I, 22)=-0,346 n s$ \\
\hline Pos_Psy_Hea & $2,15(0,55)$ & - & $2,66(0,79)$ & - & $t(I, 22)=-1,670 \mathrm{~ns}$ \\
\hline Social Integration & $2,6 I(0,42)$ & - & $2,54(0,45)$ & - & $t(I, 22)=-0,342 n s$ \\
\hline Pos_Soc_Inte & $2,77(0,39)$ & - & $2,63(0,49)$ & - & $t(I, 22)=-0,696 \mathrm{~ns}$ \\
\hline Cohabitance Satisfaction & - & $11,65(116)$ & - & $1 \mathrm{I}, 38(136,50)$ & $U(I, 22)=58,50 \mathrm{~ns}$ \\
\hline Pos_Coha_Sat & $2,55(0,72)$ & - & $\mathrm{I}, 08(\mathrm{I}, 37)$ & - & $t(I, 22)=-2,903 * *$ \\
\hline Social Relationships Satisfaction & - & II,90(II9) & - & II,I7(I34) & $U(I, 22)=56 n s$ \\
\hline Post Social Relationships Sat & $2,90(0,18)$ & - & $2,29(0,83)$ & - & $t(I, 22)=-2,148^{*}$ \\
\hline Activities Satisfaction & - & $15(150)$ & - & $8,58(103)$ & $U(I, 22)=25 * *$ \\
\hline
\end{tabular}


Table Continued..

\begin{tabular}{|c|c|c|c|c|c|}
\hline Variables & Intervenidos(N=I I) M(SD) & Mdn (IQR) & Comparación (N=I2) M(SD) & Mdn(IQR) & $\mathbf{t} / \mathbf{U}$ \\
\hline Pos Activities Satisfaction & $2,44(0,52)$ & - & $2,08(0,90)$ & - & $t(I, 22)=-I, 070 \mathrm{~ns}$ \\
\hline $\begin{array}{l}\text { Environmental Elements } \\
\text { Satisfaction }\end{array}$ & II,50(II5) & - & II,50(I38) & - & $U(1,22)=60 \mathrm{~ns}$ \\
\hline $\begin{array}{l}\text { Pos Environmental Elements } \\
\text { Satisfaction }\end{array}$ & - & $13(1 \mid 7)$ & - & $9,50(114)$ & $U(I, 22)=36 n s$ \\
\hline Housing General Satisfaction & II,50(II5) & - & II,50(138) & - & $U(1,22)=60 \mathrm{~ns}$ \\
\hline $\begin{array}{l}\text { Pos Housing General } \\
\text { Satisfaction }\end{array}$ & - & II(99) & - & II (I32) & $U(I, 22)=54 \mathrm{~ns}$ \\
\hline Life Satisfaction & $3,60(0,5 I)$ & - & $2,58(0,99)$ & - & $t(I, 22)=-2,910^{*}$ \\
\hline Pos Life Satisfaction & - & $13,89(125)$ & - & $8,83(106)$ & $\mathrm{U}(1,22)=28^{*}$ \\
\hline Social Relationships Frequency & $60,05(38,44)$ & $67(37)$ & $18,3(29,59)$ & $0(33)$ & $U(I, 40)=84,5^{* *}$ \\
\hline Pos_Soc_Rel_Freq & $2,85(0,79)$ & - & $2,75(0,68)$ & - & $t(1,22)=-2,99 \mathrm{~ns}$ \\
\hline Functional Skills & $2,12(0,88)$ & - & $2,00(1,12)$ & - & $t(I, 22)=-0,264 n s$ \\
\hline Pos_Fun_Ski & $2,23(0,59)$ & - & $2,08(0,99)$ & - & $t(1,22)=-0,408 n s$ \\
\hline Functional Autonomy & $2,10(0,99)$ & - & $2,08(I, 24)$ & - & $t(1,22)=-0,034 n s$ \\
\hline Pos_Auto_Fun & $2,66(0,7 I)$ & - & $I, 91(0,99)$ & - & $t(1,22)=-1,920 \mathrm{~ns}$ \\
\hline Daily Life Activities & $2,15(1,04)$ & - & $I, 93(I, I 2)$ & - & $t(1,22)=-0,454 n s$ \\
\hline Pos_Lif_Act & $I, 8 I(0,64)$ & - & $2,25(1,19)$ & - & $t(I, 22)=1,005 n s$ \\
\hline Activities and Leisure & $2,22(0,57)$ & - & $\mathrm{I}, 56(0,38)$ & - & $\mathrm{t}(\mathrm{I}, 22)=-3,229 * *$ \\
\hline Pos_Act_Leis & $2,38(0,29)$ & - & $1,69(0,86)$ & - & $t(I, 22)=-2,276^{*}$ \\
\hline Activities Frequency & $\mathrm{I}, 68(0,24)$ & - & $I, 5(0,36)$ & - & $t(I, 22)=-I, 236 \mathrm{~ns}$ \\
\hline Pos_Act_Fre & $1,92(0,26)$ & - & $\mathrm{I}, 49(0,64)$ & - & $t(1,22)=-1,889 \mathrm{~ns}$ \\
\hline Activity Level & - & $14(140)$ & - & $9,42(113)$ & $U(I, 22)=35^{*}$ \\
\hline Pos Activity Level & $2,77(0,66)$ & - & $I, 5(I, 3 \mid)$ & - & $t(I, 22)=-2,660 *$ \\
\hline Environmental Quality & II,50(II5) & - & II,50(138) & - & $U(1,22)=49 n s$ \\
\hline Pos Environmental Quality & - & $11,56(104)$ & - & $10,58(127)$ & $U(1,22)=49 n s$ \\
\hline Education & - & $10,30(103)$ & - & $12,50(150)$ & $U(I, 22)=48 \mathrm{~ns}$ \\
\hline Pos Education & - & $10,28(92,50)$ & - & II,54(I38,5) & $\mathrm{U}(\mathrm{I}, 22)=47,5 \mathrm{~ns}$ \\
\hline Income & - & $\mathrm{II}, 55(\mathrm{I} \mid 5,50)$ & - & II,46(I37,50) & $U(I, 22)=59,50 \mathrm{~ns}$ \\
\hline Pos Income & $1,55(1,28)$ & - & $2,54(I, I 7)$ & - & $t(I, 22)=I, 827 n s$ \\
\hline
\end{tabular}

*SD, standard deviation; IQR, interquartile range; $t$, student; $U$, mann-whitney. Data are presented as mean/deviation $t$, if they follow a normal distribution, and/ or interquartile mean/range (IQR) if they don't. $* p<.05 . * p<.01 . n s=$ not significant.

Table 2 Pre and Post Cognitive Scale of participants who collaborated in the study

\begin{tabular}{|c|c|c|c|c|c|}
\hline Variables & Intervened $(\mathrm{N}=I \mathrm{I}) \mathrm{M}(\mathrm{SD})$ & Mdn (IQR) & Comparison $(\mathrm{N}=\mid 2) \mathrm{M}(\mathrm{SD})$ & Mdn (IQR) & $t / U$ \\
\hline Orientation & $7,45(3,04)$ & - & $5,75(2,80)$ & - & $t(1,22)=-1,399 \mathrm{~ns}$ \\
\hline Post_Orientation & $7, I I(3,44)$ & - & $5,33(2,83)$ & - & $t(I, 22)=I, 297 \mathrm{~ns}$ \\
\hline Binding & - & $11,45(126)$ & - & $12,50(150)$ & $U(I, 23)=60 \mathrm{~ns}$ \\
\hline Post_Binding & - & $9,67(87)$ & - & $12(144)$ & $U(I, 2 I)=42 \mathrm{~ns}$ \\
\hline Concentration and Calculo & $4(3,52)$ & - & $2,33(2,42)$ & - & $t(I, 22)=-1,332 \mathrm{~ns}$ \\
\hline Language and Construction & $7,82(2,99)$ & - & $8,16(1,58)$ & - & $t(I, 22)=0,353 n s$ \\
\hline Post_Lang and cons & $8,88(3,17)$ & - & $8,58(1,62)$ & - & $t(1,22)=-0,288 n s$ \\
\hline Memory & - & $15,23(167,50)$ & - & $9,04(108,50)$ & $U(I, 23)=30,50 * *$ \\
\hline Post_Memory & - & $11,90(119)$ & - & $11,17(134)$ & $U(1,22)=20 * *$ \\
\hline Total Cognitive Scale & $23,54(9,84)$ & - & $19,66(4,73)$ & - & $t(I, 22)=-I, 22 I n s$ \\
\hline Post Total Cognitive Escale & $23,88(10,69)$ & - & $20,4 I(4,54)$ & - & $t(1,22)=-1,016 \mathrm{~ns}$ \\
\hline
\end{tabular}

*SD, standard deviation; IQR, interquartile range; $t$, student; $U$, mann-whitney. Data are presented as mean/deviation $t$, if they follow a normal distribution, and/or interquartile mean/range (IQR) if they don't. ${ }^{*} p<.05 .{ }^{*} p<.01 . n s$, not significant. Results show that participants do not improve memory. 


\section{Discussion and conclusion}

An objective and observable improvement is shown in participants in terms of social relations satisfaction, life satisfaction, leisure activities and activity level. It must be pointed out that the recorded sessions show a higher level of satisfaction in these fields than the one showed on the objective tests. However, this aspect is part of elderly people's idiosyncrasy, who, due to aging, not only natural but also with some type of pathology, face bigger difficulties and lower attention when it comes to paying attention to objective tests solving.

Previous checking of empirical works, and application of the present work, support that prevention programs based on activities that encourage cognitive work from the play perspective, involve interest and improve elderly people's QOL.

In conclusion, we must admit that our study does not show a significant improvement in terms of memory, however, we reckon this fact is mainly due to the lack of continuity in the program and the short time we had at our disposal in order to carry out the activities. Moreover, based on the same lack of continuity and short timing, it has been observed that these activities do improve aspects directly related to QOL, self-esteem and, in short, happiness of elderly people, even of those who present a moderate cognitive impairment. This fact shows that the activities carried out are highly potential for emotional improvement in elderly people.

It must be also pointed out, another aspect that was not initially in our field of study, which is the elderly participants' families. This investigation has aroused interest, more involvement and, as far as it was possible, higher active participation in the project from them. Relatives have grown an interest in contributing and helping when it comes to Life Stories and, they could be observed showing pride for their relatives when they observed their skills in the Eurhythmy activities. Families themselves have lived with affection the activities process, feeling surprised by all the things their relatives can still develop with the right stimulation and, recall moments from the past or even discover situations from the past about their relatives that were unknown. All in all, we consider that it is also necessary to encourage prevention programs based on non-pharmacological treatments and, from our point of view, created by professionals in order to offer a QOL and dignity based on the patients' enjoyment, strengthening their family bonds, and improving their physical and cognitive autonomy.

\section{Funding}

The authors disclosed receipt of the following financial support for the research, authorship, and/or publication of this article: Jaume I University and Residence 'Azahar del Mediterraneo' about Alzheimer and applied sciences dementias in 2014.

\section{Acknowledgments}

None.

\section{Conflicts interest}

The authors declared no potential conflicts of interest with respect to the research, authorship, and/or publication of this article.

\section{References}

1. García de Blas F. Classification of dementias. In cubero gonzález diagnosis and treatment of dementias in primary care. Barcelona: Masson; 2002

2. Lobo A, Launer LJ, Fratiglioni L, et al. Prevalence of dementia and major subtypes in Europe: a collaborative study of population-based cohorts. Neurology. 2000;54 (Suppl 5):S4-9.

3. Rocaspana C, Blanco J, Gea SM, et al. Relationship of nutritional status with cognitive, behavioral and functional function in patients with Alzheimer's disease. Ágora de enfermería. 2015;19:1575-7668.

4. Pérez SG. Intervention and integral development in elderly people. Madrid: wniversitas; 2006.

5. López M. What are life stories? unpublished document. Grupo de Investigación. HUM-246; 2007.

6. Verdugo MA, Gómez S, L Arias B. Evaluation of the quality of life in elderly people. the fumat scale. salamanca: university institute of integration in the community; 2009.

7. Ramos EJ, Figueroa OH, Marcela EC, et al. Old age and quality of life from the point of view of the elderly: a study on the social representations of a social group. Journal of Education and Development; 2013: 26.

8. Agulló MS. Seniors, activity and work in the process of aging and retirement: a psycho-sociological approach. Madrid: IMSERSO. ISBN: 84-8446-036-3 and virtual re-edition; 2001.

9. Fernández BR. Introduction to psychological evaluation II. Madrid: Pirámide; 1999 .

10. Pérez SG. Intervention and integral development in elderly people. Madrid: Universitas. 2006.

11. http://www.fundaciondelcerebro.es/docs/imp_social_alzheimer.pdf. 2011

12. http://static.correofarmaceutico.com/docs/2013/06/18/in_al.pdf

13. Lobo A, López AR, Santabárbara J, et al. Incidence and lifetime risk of dementia and Alzheimer's disease in a Southern European population. Acta Psychiatr Scand. 2011;124(5):8372-8327.

14. De Pedro CJ, Virués OJ, Vega S, et al. Prevalence of dementia and major dementia subtypes in Spanish populations: A reanalysis of dementia prevalence surveys, 1990-2008. BMC Neurology. 2009;9:55.

15. López PS, Vilalta FJ, Garre OJ, et al. Unit of Valoracío of the Memory, and the Demècies, Hospital Santa Caterina, Salt, Gerona, Spain. Revista de Neurologia. 2006; 45(11):683-688.

16. http://www.crealzheimer.es/InterPresent2/groups/imserso/documents/ binario/resolucion_alzheimer.pdf

17. Kikuchi EL. Classification of dementia syndromes. In: SMD Brucki \& RM Magaldi. editors demands: multidisciplinary approach. from pathophysiological bases to diagnosis and treatment. Atheneu: São Paulo $.2011 ; 51-55$.

18. Fernández BR. Introduction to psychological evaluation II. Madrid: Pyramid; 1999.

19. Butler RN. The life review: an interpretation of reminescence in the aged. Psychyatry. 1963;26:65-76.

20. Kiernat JM. The use of life review activity with confused nursing home residents. Am J Occupational Therapy. 1979;33:306-310.

21. Baines S, Saxby P, Ehlert K. Reality orientation and reminiscence therapy: a controlled cross-over study of elderly confused people. $\mathrm{Br} J$ Psychiatry. 1987;151:222-231.

22. Francés I, Barandian M, Marcellán T, et al. Psychocognitive stimulation in dementias. An Sist Sanit Navar. 2003;26(3):405-422.

23. Bäckman L, Josephsson S, Herlitz A. et al. The generalizability of training gains in dementia: effects of an imagery-based mnemonic on face-name retention duration. Psychol Aging. 1991;6:489-492.

24. http://hdl.handle.net/2445/32345 
25. Shopenhauer, A. The world as will and representation. Barcelona: Circle of readers; 2010

26. Ferrarotti F. Historie et Histories de vie. Paris: Les Méridiens; 1983.

27. López M. What are life stories? Unpublished document Research Group HUM-246; 2007.

28. Rivas JIY, Herrera D. Voice and education. Barcelona: Octahedron; 2009

29. Ignacio RJ, Fernando H, Juana Ma S, et al. Historias de vida en educación: sujeto, diálogo, experiencia. Red Universitaria de Investigación Innovación Educativa. 2012.

30. De la Rubia JE, Sancho P, Cabañés A. Physiological impact of music therapy on depression, anxiety, and well-being of the patient with Alzheimer's type dementia. Assessment of the use of questionnaires to quantify it. European Journal of Investigation in Health, Psychology and Education. 2014;4(2):131-140.

31. Hars M, Herrmann FR, Gold G, et al. Effect of music-based multitask training on cognition and mood in older adults. Oxford Age Ageing 2014;43:196-200.

32. Vernia AM. The Eurythmic as a Tool to Enhance memory. activities against alzheimers. Science Journal of Education. 2014;2(3):20-25.

33. Trombetti A, Hars M, Herrmann FR, et al. Effect of music-based multitask training on gait, balance, and fall risk in elderly people: a randomized controlled trial. Arch Intern Med. 2011; 171(6):525-533.

34. http://ageing.oxfordjournals.org
35. Lord TR, Garner JE. Effects of music on Alzheimer's patients. Percept Mot Skills. 1993;76(2):451-455.

36. Jacobsen JH, Stelzer J, Fritz TH. Why musical memory can be preserved in advanced Alzheimer's disease. Brain. 2015;138(Pt8):2438-2450.

37. Bugos JA, Perlstein WM, McCrae CS, et al. Individualized piano instruction enhances executive functioning and working memory in older adults. Aging Ment Health. 2007;11(4):464-471.

38. Kydd P. Using music therapy to help a client with Alzheimer's disease adapted to long-term care. Am J Alzheimers Dis Other Demen. 2001;(16)2:103-108.

39. Prickett C, Moore R. The Use of Music to aid memory of alzheimer's patients. Journal Music Therapy. 1991;28(2):101-110.

40. York E. The development of a quantitative music skills test for patients with alzheimer's disease. Journal Music Therapy. 1994;31:280-296.

41. Martí M, Nebot E. Telling me how it happened, your past and present, my future. Betxí, Ayto. Betxí; 2012.

42. Folstein MF, Folstein SE, McHugh PR. Mini-mental state. A practical method for grading the cognitive state of patients for the clinician. $J$ Psychiatr Res. 1975;12(3):189-198.

43. http://www.infogerontologia.com/documents/vgi/escalas/mini_mental. pdf

44. Fernández-Ballesteros R. Introduction to psychological evaluation II. Madrid: Pyramid; 1999. 